\title{
British Thoracic Society emergency oxygen audits
}

\author{
B R O'Driscoll, ${ }^{1}$ L S Howard, ${ }^{2}$ C Bucknall, ${ }^{3}$ S A Welham, ${ }^{4}$ A G Davison, ${ }^{5}$ On behalf of \\ the British Thoracic Society
}

'Manchester Academic Health Science Centre, University of Manchester, Salford Royal Foundation NHS Trust, Salford, UK

${ }^{2}$ Department of Respiratory Medicine, Hammersmith Hospital, London, UK

${ }^{3}$ Department of Respiratory Medicine, Stobhill Hospital, Glasgow, UK

${ }^{4}$ British Thoracic Society, London, UK

${ }^{5}$ Department of Respiratory Medicine, Southend University Hospital, Southend, UK

Correspondence to B R O'Driscoll, Department of Respiratory Medicine, Salford Royal University Hospital, Salford M6 8HD, UK; ronan.o'driscoll@srft.nhs.uk

Further details of the audit are available on the BTS website at http://www.brit-thoracic.org.uk/ clinical-information/emergencyoxygen/emergency-oxygenuse-audit-tool.aspx This report is submitted on behalf of the British Thoracic Society.

Received 23 February 2011 Accepted 4 March 2011 Published Online First 17 April 2011

\section{ABSTRACT}

The British Thoracic Society (BTS) guideline for emergency oxygen use in adult patients was commissioned by the BTS and developed in conjunction with 21 other colleges and societies prior to publication in 2008. One of the specific aims of the Guideline Development Group was to audit the use of oxygen in UK hospitals before the guideline was published and at intervals afterwards.

\section{BACKGROUND}

The national programme of British Thoracic Society (BTS) emergency oxygen audits began in 2008, immediately prior to the publication of the BTS guideline for emergency oxygen use in adult patients. ${ }^{1}$ It had been known for several decades that oxygen can be a life-saving drug for patients with severe hypoxaemia but excessive amounts of oxygen can be harmful, especially for patients with exacerbated chronic obstructive pulmonary disease (COPD) and those with other conditions which make them vulnerable to hypercapnic respiratory failure. ${ }^{1}$ Although medical oxygen is a drug, local audits in several countries have shown that there are significant problems with the use of oxygen in hospitals and in ambulances. ${ }^{1-3}$ These surveys have reported that oxygen was commonly used without any prescription and prescriptions, it they did exist, were rarely followed at the bedside. The BTS guideline for emergency oxygen use in adult patients was commissioned by the BTS and developed in conjunction with 21 other colleges and societies prior to publication in 2008. One of the specific aims of the Guideline Development Group was to audit the use of oxygen in UK hospitals before the guideline was published and at intervals afterwards.

\section{AUDIT DESIGN}

The BTS recruited medial and nursing or physiotherapy 'oxygen champions' to implement the guideline in almost all acute UK hospitals. The first task of these champions was to conduct a baseline audit in September-October 2008 to obtain a record of UK practice immediately prior to the guideline launch in October of that year. The authors report the findings of UK-wide hospital oxygen audits in 2008 and 2010 together with the results of implementation audits in 2009 and 2010.

\section{RESULTS}

\section{Oxygen prescribing}

The proportion of patients using oxygen fell from $17.5 \%$ in 2008 to $15.5 \%$ in 2010 while the proportion with a prescription rose from $32 \%$ to $56 \%$. Only $10 \%$ of patients had a prescription with target range in 2008 but this had risen to $41 \%$ by 2010 .

The key findings of the 2008 and 2010 audits are shown in table 1 .

\section{Use of oximetry and signatures for oxygen during drug rounds}

Documentation of oximetry on observation wards was high (94\%) in 2008 and further improved in 2010 (99\%). However, oxygen, unlike other drugs, was rarely signed for on drug rounds, although the rise from $5 \%$ to $16 \%$ was encouraging.

\section{Use of oxygen on different types of wards}

Individual oxygen champions can access audit results at their own hospital and compare them with national results for institutions and also for each type of ward. Figure 1 shows the different levels of oxygen use on various types of wards and units.

\section{Audit of implementation of BTS recommendations in 2009 and 2010}

Four key steps are required to implement the BTS emergency oxygen guideline in each hospital.

1. Implementation of local oxygen policy based on BTS template.

2. Introduction of standard oxygen prescribing systems.

Table 1 Main results of British Thoracic Society hospital oxygen audits in 2008 and 2010

\begin{tabular}{lllllllll}
\hline Year & $\begin{array}{l}\text { Number of } \\
\text { hospitals }\end{array}$ & $\begin{array}{l}\text { Number of } \\
\text { patients }\end{array}$ & $\begin{array}{l}\text { Number of } \\
\text { wards }\end{array}$ & 0n oxygen (\%)* & $\begin{array}{l}\text { Oxygen } \\
\text { prescribed }(\%) \dagger\end{array}$ & $\begin{array}{l}\text { Drug rounds } \\
\text { signed (\%) } \ddagger\end{array}$ & $\begin{array}{l}\text { 0ximetry } \\
\text { recorded }(\%) \S\end{array}$ & $\begin{array}{l}\text { Correct delivery } \\
\text { system (\%) }\end{array}$ \\
\hline 2008 & 99 & 14830 & 712 & 17.5 & $32(10)$ & 5 & 94 & 47 \\
2010 & 90 & 22017 & 1026 & 15.5 & $56(41)$ & 16 & 99 & 59 \\
\hline
\end{tabular}

*Patients using oxygen on the day of the audit.

†Patients using oxygen who had a valid prescription or written order (and those with a prescription with target range).

fDrug rounds on which oxygen was signed for (if patient on oxygen).

$\S$ Observation rounds during which oximetry was documented.

『Patients using the exact oxygen delivery system specified for them. 


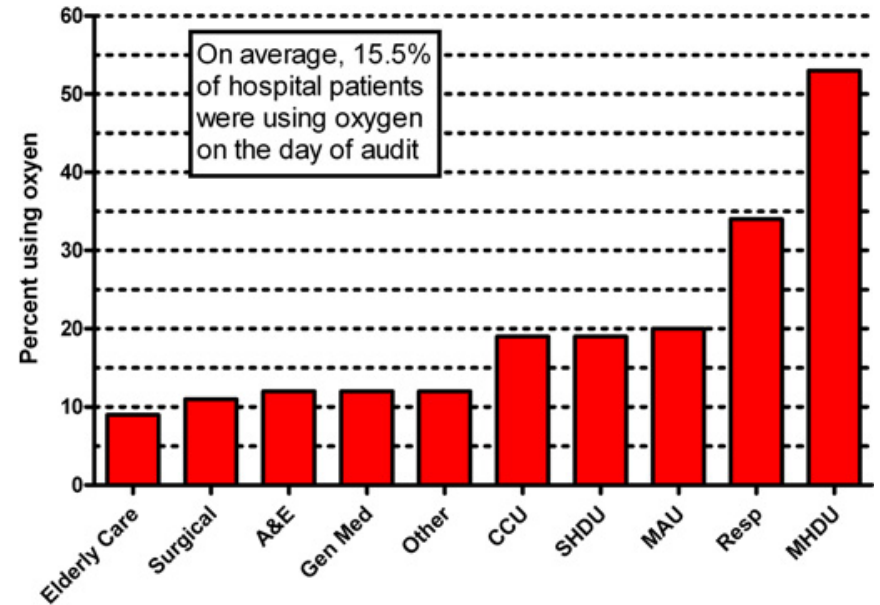

Figure 1 Percentage of patients using oxygen on each type of ward. CCU, Coronary Care Unit; SHDU, Surgical High Dependency Unit; MAU, Medical Assessment Unit; MHDU, Medical High Dependency Unit.

3. Standard bedside documentation of oxygen administration and oximetry results.

4. Training of doctors, nurses and other healthcare professionals. Table 2 shows that oxygen champions have struggled to have local oxygen policies with standardised oxygen prescribing and monitoring systems approved and implemented by their hospitals. Only $37 \%$ of responding hospitals had an approved hospital policy in 2010. The authors believe that much of the delay in modernisation of oxygen prescribing in the UK is probably because of the difficulty in changing established practices. Table 2 demonstrates that training medical and nursing staff in the safe use of oxygen has been particularly difficult.

\section{CONCLUSION AND FUTURE PLANS}

Oxygen prescribing and administration in the UK was highly unsatisfactory prior to the publication of the BTS guideline in

Table 2 Oxygen implementation audits in February 2009 and October-November 2010

\begin{tabular}{lll}
\hline & $\mathbf{2 0 0 9}(\mathbf{n}=\mathbf{7 2})(\%)$ & $\mathbf{2 0 1 0}(\mathbf{n}=\mathbf{5 1})(\%)$ \\
\hline Oxygen policy in place & 6 & 37 \\
Pre-printed oxygen prescription charts & 9 & 51 \\
Pre-printed bedside monitoring chart & 7 & 33 \\
Nurse training fully implemented & 7 & 18 \\
Doctor training fully implemented & 4 & 11 \\
\hline
\end{tabular}

\section{Learning points/action points}

- Prior to the publication of the BTS emergency oxygen guideline in 2008, most UK hospital patients who received oxygen did not have a prescription for this drug.

- The majority of patients had a prescription for oxygen in 2010 but there is still scope for major improvement in oxygen prescribing and monitoring.

- Despite the presence of oxygen champions in most UK hospitals, it is proving difficult to implement local oxygen policies based on the BTS guideline.

- Having delivered a guideline that has the support of 22 societies and colleges, the Guideline Development Group will now focus on education and implementation in addition to a planned update of the scientific content of the guideline in 2013.

2008 and is improving slowly. There are particular difficulties in trying to ensure that oxygen is prescribed, administered and monitored in the same manner as other drugs. In addition, the audit has identified delays in implementing new local oxygen policies and in training healthcare staff. These issues are being addressed by the Guideline Development Group, which is being reassembled in early 2011 to produce an updated guideline due to be published in 2013. One of the key decisions was to appoint a co-chair to lead on education of doctors and nurses (and medical and nursing students) and another co-chair to lead on implementation. With these enhancements, it is hoped that many lives will be saved by the careful and appropriate use of this important drug, which is probably the most widely used drug in emergency medicine.

Competing interests None.

Provenance and peer review Not commissioned; internally peer reviewed.

\section{REFERENCES}

1. O'Driscoll BR, Howard LS, Davison AG; British Thoracic Society. BTS guideline for emergency oxygen use in adult patients. Thorax 2008;63(Suppl 6):vi1-68.

2. Boyle M, Wong J. Prescribing oxygen therapy. An audit of oxygen prescribing practices on medical wards at North Shore Hospital, Auckland, New Zealand. N Z Med J 2006;119:U2080.

3. Kbar FA, Campbell IA. Oxygen therapy in hospitalized patients: the impact of local guidelines. J Eval Clin Pract 2006;12:31-6. 